\title{
Multifunctional Laryngeal Motoneurons: an Intracellular Study in the Cat
}

\author{
Keisuke Shiba, ${ }^{1}$ Isamu Satoh, ${ }^{1,2}$ Nobuhiro Kobayashi,, ${ }^{1,2}$ and Fumiaki Hayashi ${ }^{2}$ \\ Departments of ${ }^{1}$ Otolaryngology and ${ }^{2}$ Physiology, School of Medicine, Chiba University, Chiba City, \\ Chiba 260-0856, Japan
}

\begin{abstract}
We studied the patterns of membrane potential changes in laryngeal motoneurons (LMs) during vocalization, coughing, swallowing, sneezing, and the aspiration reflex in decerebrate paralyzed cats. LMs, identified by antidromic activation from the recurrent laryngeal nerve, were expiratory (ELMs) or inspiratory (ILMs) cells that depolarized during their respective phases in eupnea. During vocalization, most ELMs depolarized and most ILMs hyperpolarized. Some ILMs depolarized slightly during vocalization. During coughing, ELMs depolarized abruptly at the transition from the inspiratory to the expiratory phase. In one-third of ELMs, this depolarization persisted throughout the abdominal burst. In the remainder ("type A"), it was interrupted by a transient repolarization. ILMs exhibited a membrane potential trajectory opposite to that of type A ELMs during coughing. During swallowing, the membrane potential of ELMs decreased transiently at the onset of the hypoglossal burst and
\end{abstract}

then depolarized strongly during the burst. ILMs hyperpolarized sharply at the onset of the burst and depolarized as hypoglossal activity ceased. During sneezing, ELMs and ILMs exhibited membrane potential changes similar to those of type A ELMs and ILMs during coughing. During the aspiration reflex, ELMs and ILMs exhibited bell-shaped hyperpolarization and depolarization trajectories, respectively. We conclude that central drives to LMs, consisting of complex combinations of excitation and inhibition, vary during vocalization and upper airway defensive reflexes. This study provides data for analysis of the neuronal networks that produce these various behaviors and analysis of network reorganization caused by changes in dynamic connections between the respiratory and nonrespiratory neuronal networks.

Key words: laryngeal motoneuron; vocalization; coughing; swallowing; sneezing; aspiration reflex; decerebrate cat
The larynx, phylogenetically an organ for protecting the airway, acquired a vocal function during the process of evolution. Accordingly, opening or closing of the glottis serves several functions, including respiration, airway protection, and vocalization. In eupnea, the vocal fold is abducted during inspiration to decrease airway resistance and is slightly adducted during expiration, which brakes expiratory airflow and so limits collapse of the lung (Bartlett, 1986). During vocalization, forced expiratory airflow with glottal narrowing vibrates the vocal cords. Various laryngeal movements occur during defensive reflexes. For example, in both coughing and sneezing, there is a series of movements consisting of glottal closure during forced expiration, followed by transient glottal opening, which results in an explosive expiratory airflow that expels foreign bodies from the upper airways (Korpas and Tomori, 1979). Swallowing-related glottal closure protects the lower airway from aspiration. In the aspiration reflex, short powerful inspiratory efforts with the glottis open would clear irritants from the nasopharynx (Korpas and Tomori, 1979; Widdicombe, 1986). Although the larynx plays a critical role in these behaviors, little is known about the central mechanisms that drive laryngeal motoneurons in response to sensory stimuli. How do animals use the same peripheral structures to generate different

\footnotetext{
Received Nov. 7, 1998; revised Jan. 11, 1999; accepted Jan. 17, 1999.

This work was supported in part by Grant-in-Aid 09771330 for Scientific Research from the Japanese Ministry of Education, Science, and Culture. We thank Drs. Yoshio Nakajima, Akiyoshi Konno, and Toshiro Umezaki for comments on this manuscript and for continuous encouragement.

Correspondence should be addressed to Dr. Keisuke Shiba, Department of Otolaryngology, School of Medicine, Chiba University, 1-8-1 Inohana, Chuo-ku, Chiba City, Chiba 260-0856, Japan.

Copyright (ㄷ) 1999 Society for Neuroscience $\quad 0270-6474 / 99 / 192717-11 \$ 05.00 / 0$
}

behavioral responses? In the present study, we monitored membrane potential changes in laryngeal motoneurons to determine the nature of their central drives during vocalization and upper airway defensive reflexes, including coughing, sneezing, swallowing, and the aspiration reflex. This study will provide data for analysis of neuronal networks that produce these behaviors and will help to reveal neural architectures that cause the same peripheral structures to yield different adaptive behaviors in response to sensory stimuli.

Fictive behavior models in paralyzed animals allow stable neuronal recordings by eliminating animal movements and simplify the analysis of neural activities by removing movement-related feedback inputs. Thus, we recorded membrane potentials in laryngeal motoneurons during fictive vocalization (Shiba et al., 1996), fictive coughing (Bolser, 1991; Grélot and Milano, 1991), fictive sneezing (Satoh et al., 1998), fictive swallowing (Nishino et al., 1985; Umezaki et al., 1998), and the fictive aspiration reflex (Jodkowski et al., 1989) in paralyzed, artificially ventilated cats. The intralaryngeal muscles consist of the vocal fold adductors, abductor, and tensor. These muscles are innervated by the recurrent laryngeal nerve (RLN), except the vocal fold tensor, i.e., cricothyroid muscle, which is innervated by efferents from the superior laryngeal nerve (SLN). In the present study, we performed intracellular recordings from laryngeal motoneurons activated antidromically from the RLN, i.e., motoneurons of intralaryngeal muscles other than the cricothyroid. Barillot et al. (1990) reported that laryngeal motoneurons consist of inspiratory laryngeal motoneurons (ILMs) that depolarize during inspiration and expiratory laryngeal motoneurons (ELMs) that depolarize during expiration. Because the adductor and abductor 


\begin{tabular}{|c|c|c|c|c|c|c|c|c|c|}
\hline & $\mathrm{V}$ & $\mathrm{C}$ & $\mathrm{V}+\mathrm{C}$ & $\mathrm{C}+\mathrm{SW}$ & $\mathrm{V}+\mathrm{C}+\mathrm{SW}$ & $\mathrm{V}+\mathrm{C}+\mathrm{SW}+\mathrm{SN}$ & $\mathrm{C}+\mathrm{SW}+\mathrm{SN}+\mathrm{A}$ & $\mathrm{V}+\mathrm{C}+\mathrm{SW}+\mathrm{SN}+\mathrm{A}$ & Total \\
\hline ELMs & 41 & 3 & 0 & 2 & 2 & 1 & 1 & 4 & 55 \\
\hline ILMs & 7 & 6 & 4 & 2 & 3 & 0 & 0 & 5 & 27 \\
\hline Total & 48 & 9 & 4 & 4 & 5 & 1 & 1 & 9 & 82 \\
\hline
\end{tabular}

V, Vocalization; C, coughing; SW, swallowing; SN, sneezing; A, aspiration reflex. Number of laryngeal motoneurons studied during behaviors are indicated.

muscles are activated during the expiratory and inspiratory phases in eupnea, respectively (Wyke and Kirchner, 1976; Bartlett, 1986), ELMs and ILMs are thought to correspond to the adductor and abductor motoneurons, respectively.

\section{MATERIALS AND METHODS}

General procedures. All the procedures used in this study conform to the NIH Guide for the Care and Use of Laboratory Animals and the Chiba University Guide for Animal Experimentation.

Data were obtained from 17 adult cats of either sex. The animals were initially anesthetized with halothane $(1.0-3.0 \%)$ vaporized in $50 \%$ nitrous oxide $-50 \%$ oxygen and were decerebrated at the precollicular level after bilateral ligation of the common carotid arteries. Dexamethasone (1 $\mathrm{mg} / \mathrm{kg}$, i.m. $)$ and atropine $(0.1 \mathrm{mg} / \mathrm{kg}$, i.m.) were administrated to minimize brain edema and to reduce secretion in the airways, respectively. The trachea was cannulated by inserting the horizontal portion of a T-shaped tube into the rostral and caudal tracheal cut ends. Cannulas were placed in the femoral artery to monitor blood pressure and in the femoral veins for drug administration. Mean blood pressure was maintained above $90 \mathrm{mmHg}$, if necessary, using intravenous infusion of suprifen hydrochloride $(0.05 \mathrm{ml} / \mathrm{kg})$. Animals were placed in a stereotaxic frame, and the dorsal surface of the medulla was exposed for recording. The caudalmost $2-4 \mathrm{~mm}$ of cerebellum was sometimes aspirated to facilitate inserting electrodes. Rectal temperature was kept at $36-37.5^{\circ} \mathrm{C}$ using a heating lamp. Anesthesia was discontinued after the completion of all surgical procedures and at least $1 \mathrm{hr}$ before data collection. At the end of each experiment, the animal was killed by an overdose of sodium pentobarbital.

Induction of vocalization. To induce vocalization, a tungsten microelectrode (tip impedance, 9-12 M 2 ; model 25-08-3; Frederick Haer \& Co., Bowdoinham, ME) was inserted into the periaqueductal gray (PAG) [Horsley-Clarke stereotaxic coordinates: anterior (A), 1.0-2.5; left (L) or right (R), 1.0-2.0; horizontal $(\mathrm{H}),+2.0-0$ ] before induction of paralysis (Jürgens, 1994; Z hang et al., 1994). Microstimulation (pulse duration, 0.2 msec; frequency, $100 \mathrm{~Hz}$; intensity, $30-150 \mu \mathrm{A}$; stimulus duration, 1-5 $\mathrm{sec}$ ) was delivered with tracking steps of $0.5 \mathrm{~mm}$ to identify the call site. PAG stimulation can induce "meow" or "hiss" vocalization (Zhang et al., 1994). We only analyzed meow vocalization. When PAG stimulation induced hiss vocalization, we proceeded to a stimulus site where only meow vocalization was induced. When the stimulus threshold for vocalization was over $150 \mu \mathrm{A}$ in the PAG or if we could not find a PAG stimulus site where only meow vocalization was induced, we changed the stimulus site to the pontine call site (PCS) [Horsley-Clarke stereotaxic coordinates: posterior, 2.0-A, 1.0; $\mathrm{L}$ or $\mathrm{R}, 3.0-5.0 ; \mathrm{H},-4.5$ to -6.0$]$, which is thought to be part of the descending pathway from the PAG to the lower brainstem conveying information necessary for vocalization (Kanai and Wang, 1962; de Lanerolle, 1990; Wada, 1994; Sakamoto et al., 1996b). The electrode was fixed at the site where the stimulus threshold for vocalization was lowest. The stimulus intensity was set at 1.5 times this vocal threshold for the remainder of the experiment.

After a stimulating electrode was fixed in the PAG or PCS, the animal was paralyzed with pancuronium bromide (initially $0.3 \mathrm{mg} / \mathrm{kg}$, i.v., and then $0.15 \mathrm{mg} \cdot \mathrm{kg}^{-1} \cdot \mathrm{hr}^{-1}$ ) and artificially ventilated with room air $\left(20-24\right.$ cycles/min). End-tidal $\mathrm{CO}_{2}$ was kept at $4-5 \%$. Bilateral pneumothoraces were made to reduce respiratory movements of the brainstem.

Recordings of nerve activities and membrane potentials. Bipolar silver cuff electrodes were placed around the C5 phrenic, L1 abdominal, and lateral branch of the hypoglossal (lat-XII) nerves for recording, around both SLNs for recording and stimulation, and around both RLNs for stimulation. The lat-XII innervates the styloglossus muscle, i.e., the elevator of the posterior tongue (Gilliam and Goldberg, 1995). Activities of these nerves were amplified, full-wave rectified, and low-pass filtered (time constant, $1 \mathrm{msec})$. Using low-impedance (1-3 M $\Omega$ ) glass electrodes containing $3 \mathrm{M} \mathrm{KCl}$, we located the laryngeal motoneuron pool while stimulating the RLN to evoke an antidromic field potential. When the laryngeal motoneuron pool was located, the recording electrode was switched to a $7-25 \mathrm{M} \Omega$ glass electrode containing $3 \mathrm{M} \mathrm{KCl}$ or $2 \mathrm{M} \mathrm{K}$ citrate for intracellular recordings. Laryngeal motoneurons were identified by antidromic activation from the RLN, which was not preceded by EPSPs. For each laryngeal motoneuron, the membrane potential was defined as the difference between the intracellular and extracellular potentials, using as a reference a single grounded $\mathrm{Ag} / \mathrm{AgCl}_{2}$ electrode inserted into the temporalis muscle. Membrane potentials and nerve activities were stored on tapes and sampled at 20 and $2 \mathrm{kHz}$, respectively, using a Cambridge Electronic Design (Cambridge, UK) 1401-plus data interface and Spike 2 software in conjunction with a Power Macintosh (7300/180) computer.

Preparation and identification of fictive behavior models. Fictive vocalization was evoked by electrical stimulation of the PAG or PCS as described above. Fictive coughing and swallowing were evoked by electrical stimulation of the SLN (pulse duration, $0.2 \mathrm{msec}$; frequency, $10 \mathrm{~Hz}$; intensity, 30-150 $\mu \mathrm{A})$. Stimulus intensity was determined by the method of Oku et al. (1994). Fictive sneezing was evoked by mechanical stimulation of the nasal mucosa with a fine polyethylene tube.

Mechanical stimulation of the nasopharyngeal mucosa can elicit an aspiration reflex consisting of powerful contractions of the diaphragm not followed by active expiration (Korpas and Tomori, 1979). Some authors have placed reliance on phrenic activity alone to define the aspiration reflex in paralyzed animals (Jodkowski et al., 1989; Fung et al., 1995). However, we believe that to identify the fictive aspiration reflex in paralyzed cats, it is necessary to compare respiratory muscle and nerve activity before and after paralysis, and furthermore, because the aspiration reflex is characterized by powerful diaphragmatic activation without subsequent active expiration, that recording from the abdominal nerve is necessary. We compared changes in activities of the phrenic, abdominal, and lat-XII nerves during nasopharyngeal stimulation after induction of paralysis, with the activities of muscles innervated by them during the reflex induced before paralysis. Thus, bipolar stainless steel wire electrodes (diameter, $50 \mu \mathrm{m}$ ) were implanted in the diaphragm, external oblique, and styloglossus muscles. A fine needle connected to a pressure transducer was inserted into the trachea to record tracheal pressure. The technique of recording from these muscles was the same as for nerves. We evoked both the real and the fictive aspiration reflexes by touching the nasopharynx with a polyethylene tube inserted through the nasal cavity.

Data analysis. For each laryngeal motoneuron, the amplitudes of respiratory-related depolarization and hyperpolarization were averaged over three consecutive respiratory cycles for each behavior. For fictive behaviors, mean values were calculated using three episodes of a given behavior. We defined the resting potentials of ELMs and ILMs as their end-inspiratory and end-expiratory membrane potentials as determined by the timing of phrenic nerve activity. The amplitudes of peak depolarization and hyperpolarization were measured from these resting potentials. When a neuron discharged, the amplitude of depolarization was defined as the maximum value of the threshold depolarization level at which an action potential was generated. Statistical comparisons of changes in membrane potentials were performed using a one-way ANOVA. Differences were considered significant at $p<0.05$. Group data were expressed as mean $\pm \mathrm{SD}$.

\section{RESULTS}

All 82 laryngeal motoneurons recorded exhibited the respiratoryrelated modulation in membrane potential changes. Of these, 55 neurons depolarized during the expiratory phase and 27 during the inspiratory phase (Table 1). Thus, we could classify all recorded laryngeal motoneurons as ELMs or ILMs as defined by 

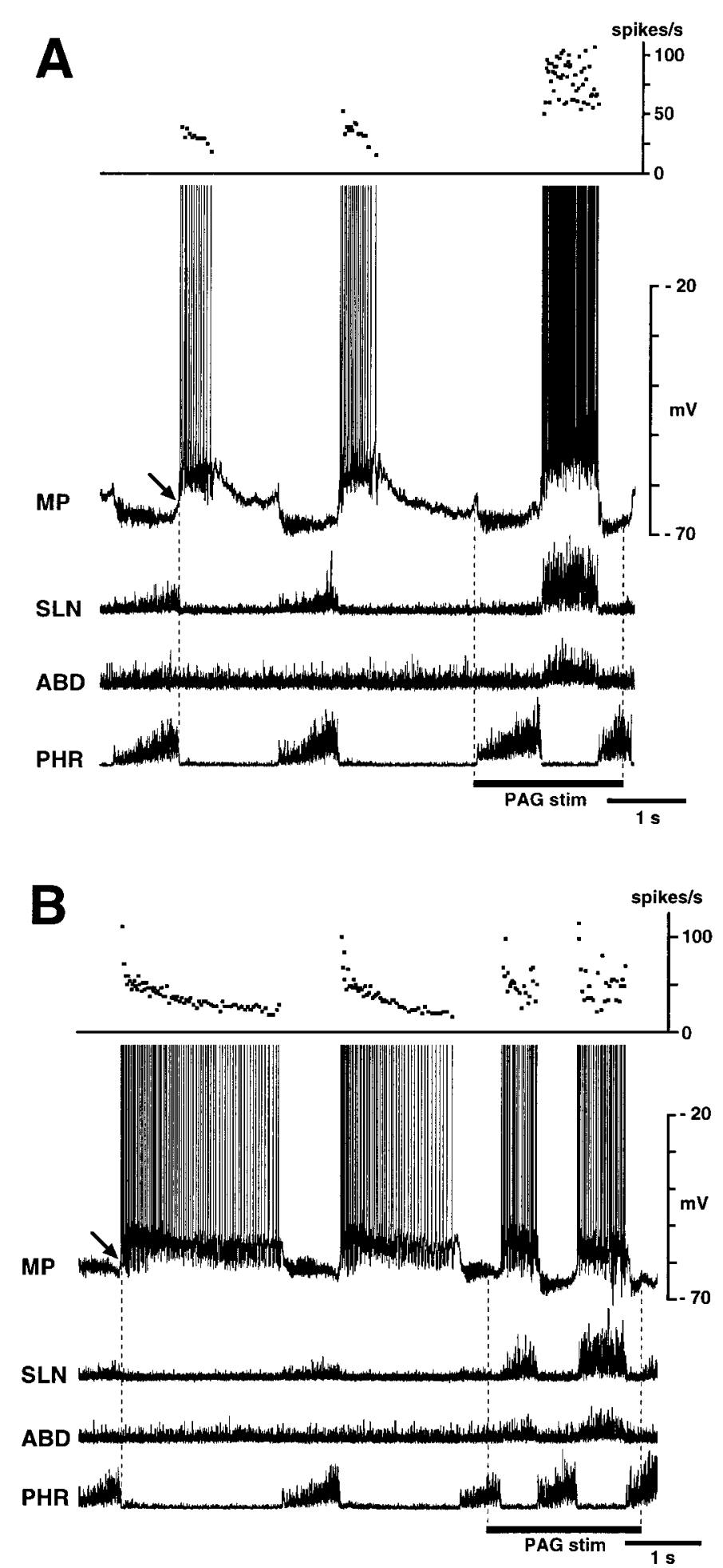

Figure 1. Behavior of ELMs during fictive vocalization. Membrane potential $(M P)$ changes in two ELMs are shown in $A$ and $B$ with integrated activities of the phrenic $(P H R)$, abdominal $(A B D)$, and superior laryngeal $(S L N)$ nerves. Vocalization is identified by strong expiratory phase activity in both the SLN and abdominal nerve during stimulation of the periaqueductal gray ( $P A G$ stim). A, This ELM depolarized powerfully during the vocal phase; the depolarization was larger than expiratory phase depolarization. Top panel shows increase instantaneous discharge frequencies during vocalization. $B$, In this ELM, the level of vocalizationrelated depolarization was similar to expiratory phase depolarization. Top panel shows lack of increase in discharge frequencies during vocalization. In both neurons, PAG stimulation changed the decrementing
Barillot et al. (1990). Antidromic latencies of ELMs and ILMs averaged $4.9 \pm 2.1$ and $5.1 \pm 1.1 \mathrm{msec}$, respectively.

\section{Fictive vocalization}

Fictive vocalization was characterized by bursting activities of the SLN and the abdominal nerve (Shiba et al., 1996). The activity of the SLN efferents during the expiratory phase was particularly important for identifying fictive vocalization. In eupnea, this nerve is usually active during inspiration. PAG and PCS stimulation caused the period of SLN activation to switch to the expiratory phase with much greater amplitude than in eupnea (Figs. 1, 2). Thus, we regarded SLN burst activity during the expiratory phase as an indicator of vocalization.

We recorded membrane potential changes in 48 ELMs and 19 ILMs during fictive vocalization. Figure 1 shows two examples of membrane potential changes in ELMs during PAG stimulation. During fictive vocalization, ELMs usually depolarized abruptly at the onset of SLN burst (Fig. 1 $A$ ). The amplitude of this depolarization $(7.8 \pm 4.3 \mathrm{mV}$; range, $1.0-19 \mathrm{mV})$ was greater than that of the control expiratory depolarization $(4.8 \pm 3.8 \mathrm{mV}$; range, $1.0-12 \mathrm{mV})(p<0.01)$. Both the mean and peak discharge frequencies of ELMs were usually increased during vocalization (Fig. $1 A$ ). In 8 of 48 ELMs, the amplitude of the vocal-related depolarization was similar to that of eupnic expiratory-related depolarization (Fig. 1B). In both these types of ELM, the decrementing pattern of membrane potential trajectory during the expiratory phase changed to a bell-shaped pattern or a plateau during vocalization. Both types of ELMs were recorded during PAG and PCS stimulation. No ELM exhibited vocalrelated depolarization smaller than control expiratory-related depolarization.

ILMs depolarized immediately after the onset of call site stimulation with a latency of $<0.1 \mathrm{sec}$ (Fig. $2 A, B$ ). The amplitude of depolarization during the inspiratory phase during stimulation $(6.5 \pm 4.4 \mathrm{mV}$; range, $1.7-16.5 \mathrm{mV})$ was greater than control depolarization $(4.9 \pm 3.6 \mathrm{mV}$; range, $0.7-11.5 \mathrm{mV})(p<0.05)$. In the majority (15 of 19$)$ of ILMs, the membrane potential repolarized abruptly at the transition from the inspiratory to the vocal phase (Fig. $2 A$ ). In these ILMs, the amplitude of vocal-related hyperpolarization $(-5.1 \pm 3.4 \mathrm{mV}$; range, -0.8 to $-8.8 \mathrm{mV})$ were greater than that of control expiratory hyperpolarization $(-1.9 \pm 1.2 \mathrm{mV}$; range, -0.8 to $-4.0 \mathrm{mV})(p<0.05)$, and the augmenting pattern of membrane potential trajectory changed to a bell-shaped or decrementing pattern during stimulusinduced inspiration and to a plateau during vocalization (Fig. $2 A$ ). Some ILMs (4 of 19) remained depolarized during vocalization (Fig. $2 B$ ); one was recorded during PAG stimulation and three during PCS stimulation. In these ILMs, the amplitude of the vocal-related depolarization averaged $3.2 \pm 1.5 \mathrm{mV}$ (range, $1.5-4.5 \mathrm{mV}$ ).

\section{Fictive coughing}

Fictive coughing was characterized by bursting activity in the abdominal nerve preceded by increased and prolonged phrenic

pattern of membrane potential trajectory during expiratory-related depolarization to a bell-shaped pattern during vocalization-related depolarization. Presumptive resting potentials of these ELMs, defined as their end-inspiratory membrane potentials, were measured at arrows. Periods of PAG stimulation are indicated by bars. Data in $A$ and $B$ were obtained from the same cat. 
Figure 2. Behavior of two ILMs during fictive vocalization induced by stimulation of the pontine call site (PCS stim).A, This neuron hyperpolarized during the vocal phase and depolarized during the stimulus-induced inspiratory phase. $B$, This neuron depolarized not only during the stimulus-induced inspiratory phase but also during the vocal phase. In both neurons, mean discharge frequencies increased during the stimulus-induced inspiratory phase compared with the control inspiratory phase (top panels). Presumptive resting potentials of these ILMs, defined as their end-expiratory membrane potentials, were measured at arrows.
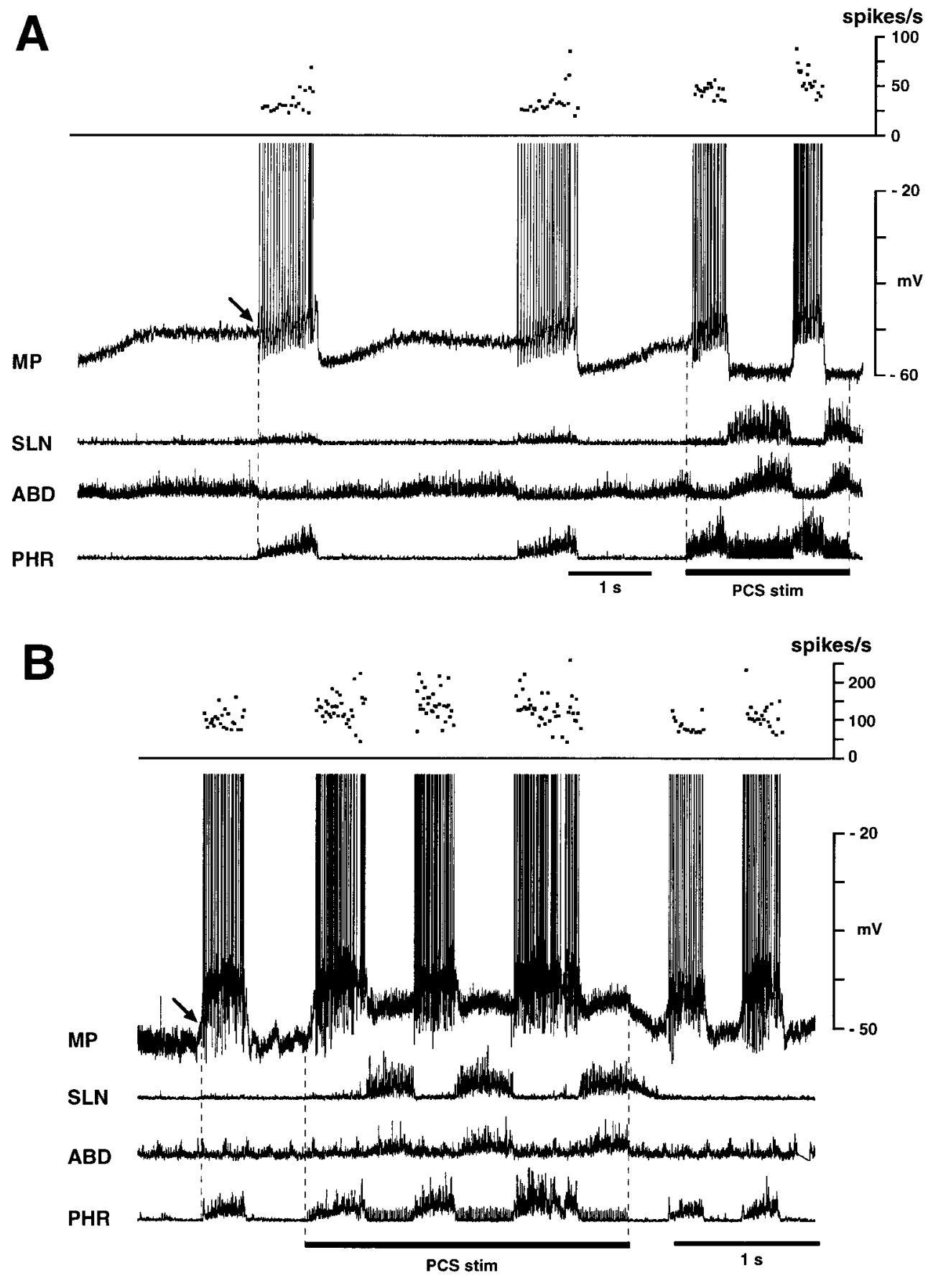

activity (Figs. 3-5) (Bolser, 1991; Grélot and Milano, 1991). We recorded membrane potential changes in 13 ELMs and 20 ILMs during fictive coughing. ELMs hyperpolarized during the augmented phrenic discharge (stage C1) and then depolarized strongly at the transition from the inspiratory to the expiratory phase (I-E transition) (stage C2) (Fig. 3B). The abdominal nerve began to burst $31 \pm 8 \mathrm{msec}$ after the onset of ELM depolarization. In 8 of the 13 ELMs, the membrane potential repolarized transiently after this depolarization (stage C3) and then depolarized again for the remainder of the abdominal burst (stage C4) (Fig. 3B). We termed these "type A" ELMs. The amplitude and duration of their depolarization during $\mathrm{C} 2$ averaged $13.7 \pm 3.2$ $\mathrm{mV}$ (range, $11-18 \mathrm{mV}$ ) and $0.14 \pm 0.02 \mathrm{sec}$, respectively. The membrane potential difference between $\mathrm{C} 2$ and $\mathrm{C} 3$ averaged
$5.9 \pm 1.8 \mathrm{mV}$ (range, $1.8-10.1 \mathrm{mV}$ ). The duration of the repolarization during $\mathrm{C} 3$ averaged $0.11 \pm 0.02 \mathrm{sec}$. Both the depolarization during $\mathrm{C} 2(p<0.05)$ and that during $\mathrm{C} 4(13.9 \pm 2.8 \mathrm{mV}$; range, $11-18 \mathrm{mV})(p<0.05)$ were greater than expiratoryrelated depolarization $(7.7 \pm 2.8 \mathrm{mV}$; range, $5.0-11 \mathrm{mV})$. In the other five ELMs, depolarization persisted after the I-E transition without transient repolarization (Fig. 4). We termed these "type B" ELMs. In type B ELMs, the amplitude of the depolarization during the abdominal burst $(14.3 \pm 5.3 \mathrm{mV}$; range, $8.0-20.0 \mathrm{mV})$ was greater than that of control expiratory-related depolarization $(9.3 \pm 3.8 \mathrm{mV}$; range, $4.0-12.0 \mathrm{mV})(p<0.05)$. There was no significant difference in the amplitude of depolarization at the I-E transition of coughing between types A and B ELMs. Discharge frequencies during the expiratory phase of coughing were 


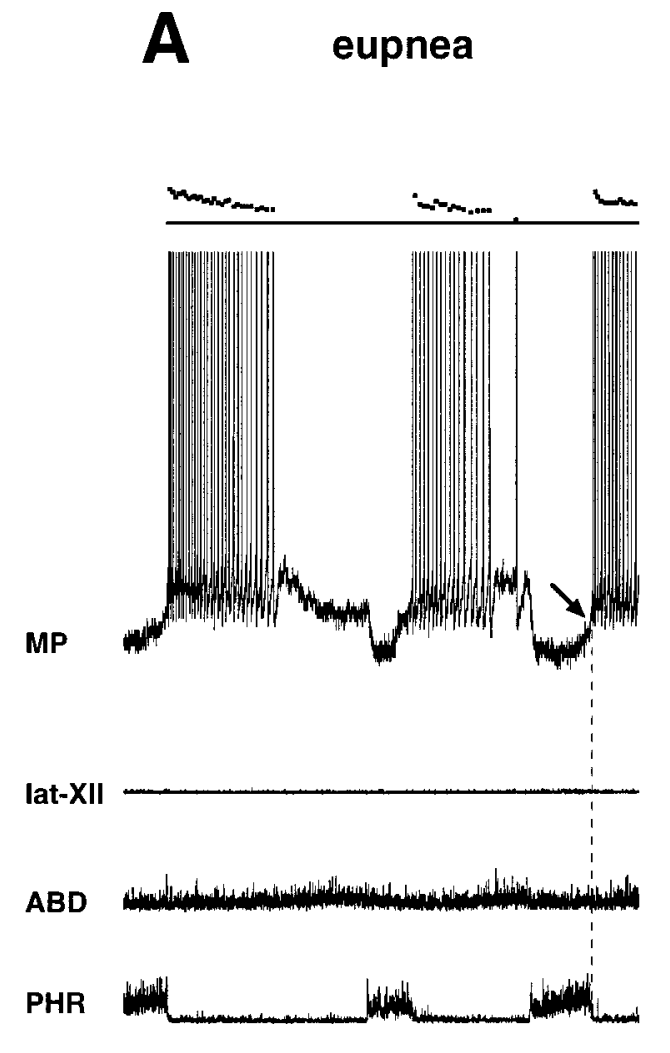

\section{B coughing and swallowing spikes/s}

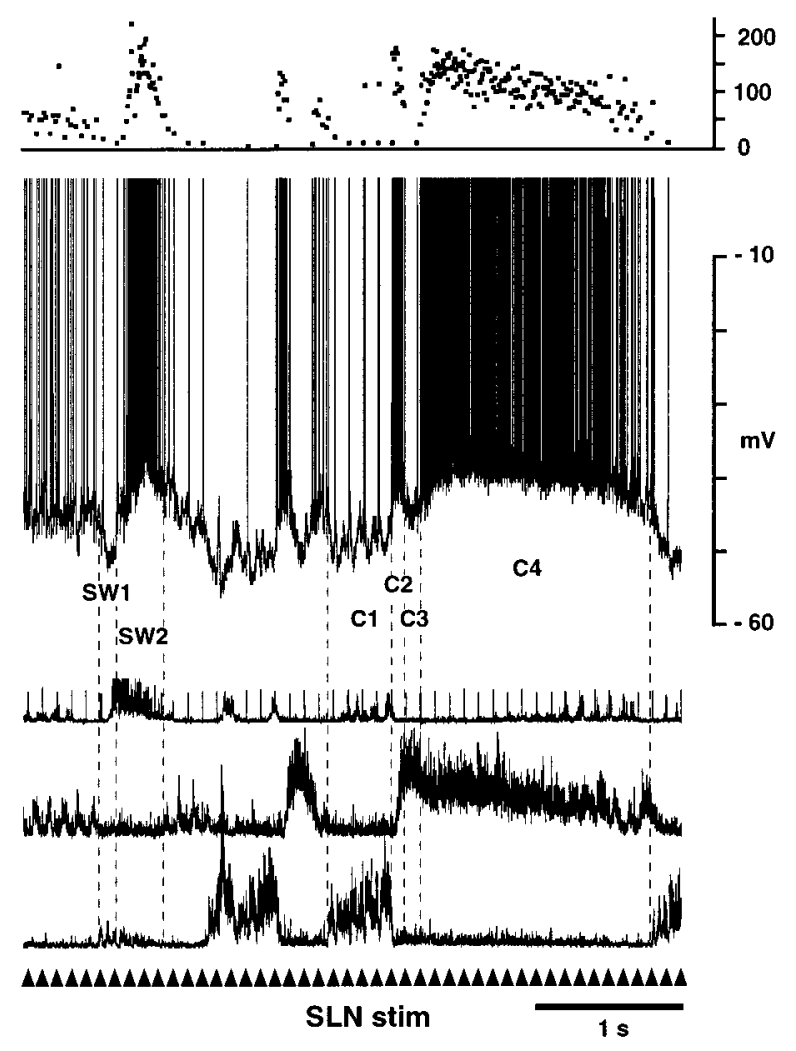

Figure 3. Membrane potential changes in a type A ELM during fictive coughing and swallowing. $A$ and $B$ were recorded during eupnea and SLN stimulation, respectively. In $B$, fictive swallowing is identified by the burst of the lat-XII. Membrane potential fell before the swallow-related hypoglossal burst $(S W 1)$ and then abruptly increased for the remainder of the hypoglossal burst (SW2). Fictive coughing is identified by the abdominal nerve burst after phrenic activation. Two episodes of cough are shown. This neuron hyperpolarized during the inspiratory phase of coughing $(C 1$, labeled in the second cough episode), depolarized briefly during the transition from the inspiratory to the expiratory phase of coughing (I-E transition) ( $C 2$ ), repolarized transiently $(C 3)$, and then depolarized again $(C 4)$. Note that firing ceased during $\mathrm{C} 3$. The $\mathrm{C} 4$ depolarization was maintained for the duration of the abdominal burst. Repetitive stimulation of the SLN $(10 \mathrm{~Hz})$ was applied at the arrowheads. Presumptive resting potential of this ELM was measured at the arrow.

increased up to $100 \mathrm{~Hz}$, as shown in Figures 3 and 4. Individual SLN stimulation evoked EPSPs. When two coughing episodes occurred consecutively, the expiratory phase of the preceding one tended to become shorter.

All 20 ILMs exhibited membrane potential trajectories opposite to those of type A ELMs during coughing. ILMs depolarized during the inspiratory phase of coughing (stage $\mathrm{C} 1$ ) and then hyperpolarized sharply at the I-E transition (stage C2) (Fig. 5). This hyperpolarization, the onset of which slightly preceded the abdominal burst, lasted for $0.12 \pm 0.05 \mathrm{sec}$. Subsequently, the membrane potential depolarized again (stage $\mathrm{C} 3$ ) and then repolarized slowly during the remainder of the burst (stage C4) (Fig. 5). The amplitude of the initial depolarization during C1 (4.4 \pm $1.7 \mathrm{mV}$; range, $1.6-6.3 \mathrm{mV}$ ) was greater than control inspiratoryrelated depolarization $(3.5 \pm 1.7 \mathrm{mV}$; range, $1.0-5.3 \mathrm{mV})(p<$ $0.01)$. Neither the amplitude of the hyperpolarization during $\mathrm{C} 2$ $(-4.1 \pm 2.7 \mathrm{mV}$; range, -0.5 to $-10.0 \mathrm{mV})$ nor during $\mathrm{C} 4$ $(-3.9 \pm 2.0 \mathrm{mV}$; range, -1.2 to $-7.2 \mathrm{mV})$ differed from that of control expiratory-related hyperpolarization $(-3.5 \pm 1.7 \mathrm{mV}$; range, -1.0 to $-5.3 \mathrm{mV})$. The amplitude of the depolarization during $\mathrm{C} 3$ averaged $0.65 \pm 1.96 \mathrm{mV}$ (range, $-2.0-5.1 \mathrm{mV}$ ). The duration of this depolarization averaged $0.14 \pm 0.05 \mathrm{sec}$. No ILM exhibited membrane potential trajectories opposite to that of type
B ELMs, i.e., no ILM hyperpolarized continuously throughout the abdominal burst.

\section{Fictive swallowing}

Fictive swallowing was characterized by bursting activity of the hypoglossal nerve, frequently accompanied by a brief burst of phrenic nerve activity, during laryngeal afferent stimulation (Figs. 3-5) (Nishino et al., 1985; Grélot et al., 1992; Oku et al., 1994; Umezaki et al., 1998). We regarded SLN-induced burst activity of the lat-XII as an indicator of fictive swallowing, because the styloglossus muscle innervated by the lat-XII is activated during the pharyngeal stage (Doty and Bosma, 1956; Amri et al., 1989).

We recorded membrane potential changes in 10 ELMs and 10 ILMs during fictive swallowing. The membrane potential of ELMs decreased briefly for $0.19 \pm 0.10 \mathrm{sec}$ at the onset of the swallow-related hypoglossal burst (stage SW1) (Figs. 3, 4). Subsequently, ELMs depolarized strongly during the hypoglossal burst (stage SW2) (Figs. 3, 4). The change in membrane potential during SW1 was $5.6 \pm 1.8 \mathrm{mV}$ (range, 3.5-8.0 mV). The amplitude of the swallow-related depolarization (SW2) $(13.7 \pm 3.5 \mathrm{mV}$; range, $7.5-17.0 \mathrm{mV}$ ) was greater than that of control expiratoryrelated depolarization $(8.4 \pm 3.0 \mathrm{mV}$; range, $5.0-12.0 \mathrm{mV})(p<$ 
Figure 4. Intracellular activity of a type B ELM during coughing $(C)$ and swallowing $(S W)$. This neuron remained depolarized throughout the abdominal burst, without a repolarization (compare with stage $\mathrm{C} 3$ in Fig. 3 ). In both this and Figure 3, the onset of depolarization at the I-E transition preceded the abdominal burst slightly. The peak discharge frequencies of both neurons increased up to $100 \mathrm{~Hz}$ during coughing and swallowing. Data in this and Figure 3 were obtained from the same cat. Presumptive resting potential of this ELM was measured at the arrow.

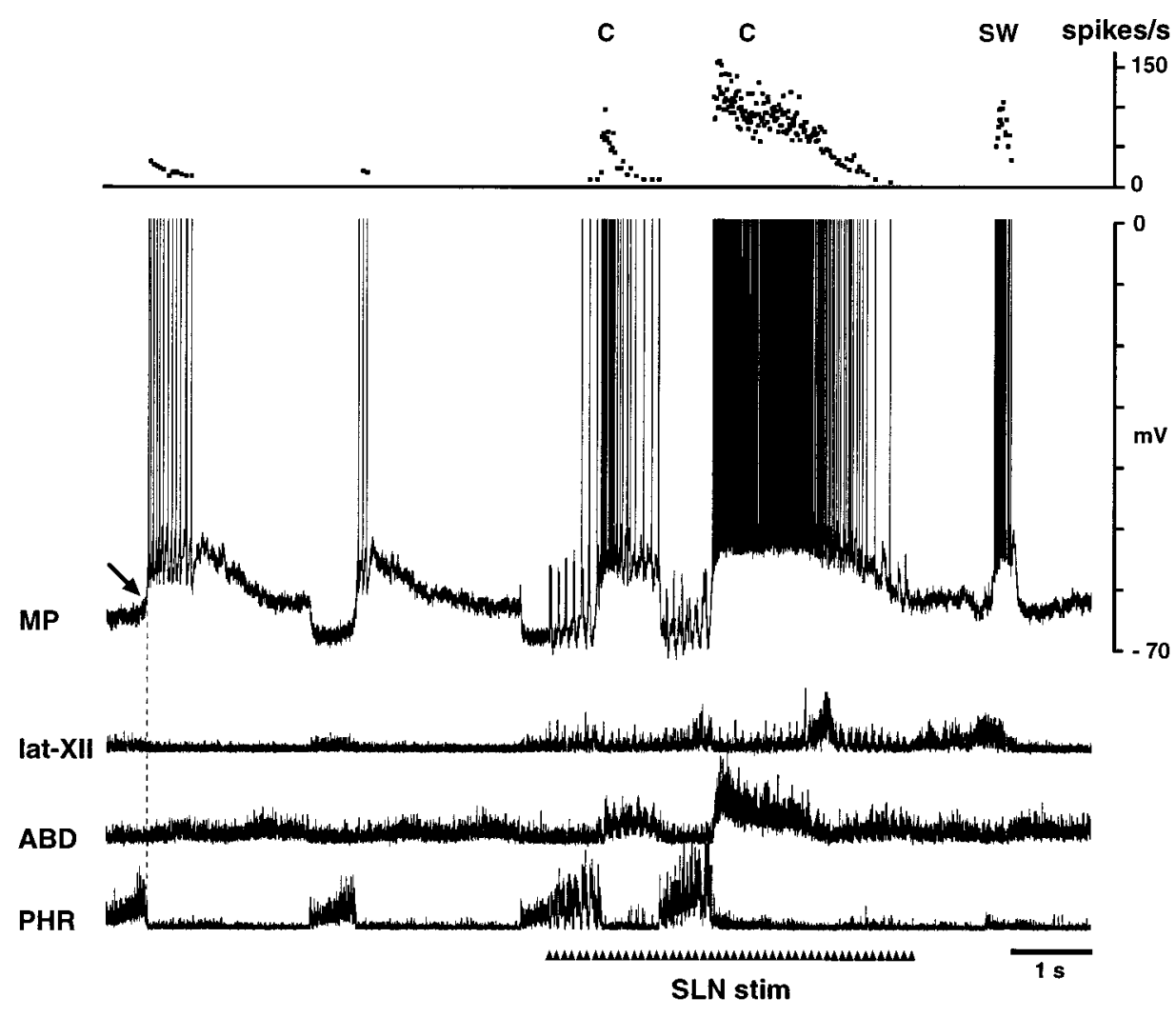

Figure 5. Membrane potential changes related to coughing and swallowing in an ILM during SLN stimulation (arrowheads). Note the depolarization during the inspiratory phase of coughing $(C 1)$, followed by abrupt hyperpolarization at the I-E transition (C2), transient hyperpolarization $(C 3)$, and gradual repolarization during the residual abdominal burst (C4). This neuron hyperpolarized abruptly during the swallow-related hypoglossal burst $(S W 2)$ and then depolarized in $S W 3$. Presumptive resting potential of this ILM was measured at the arrow.

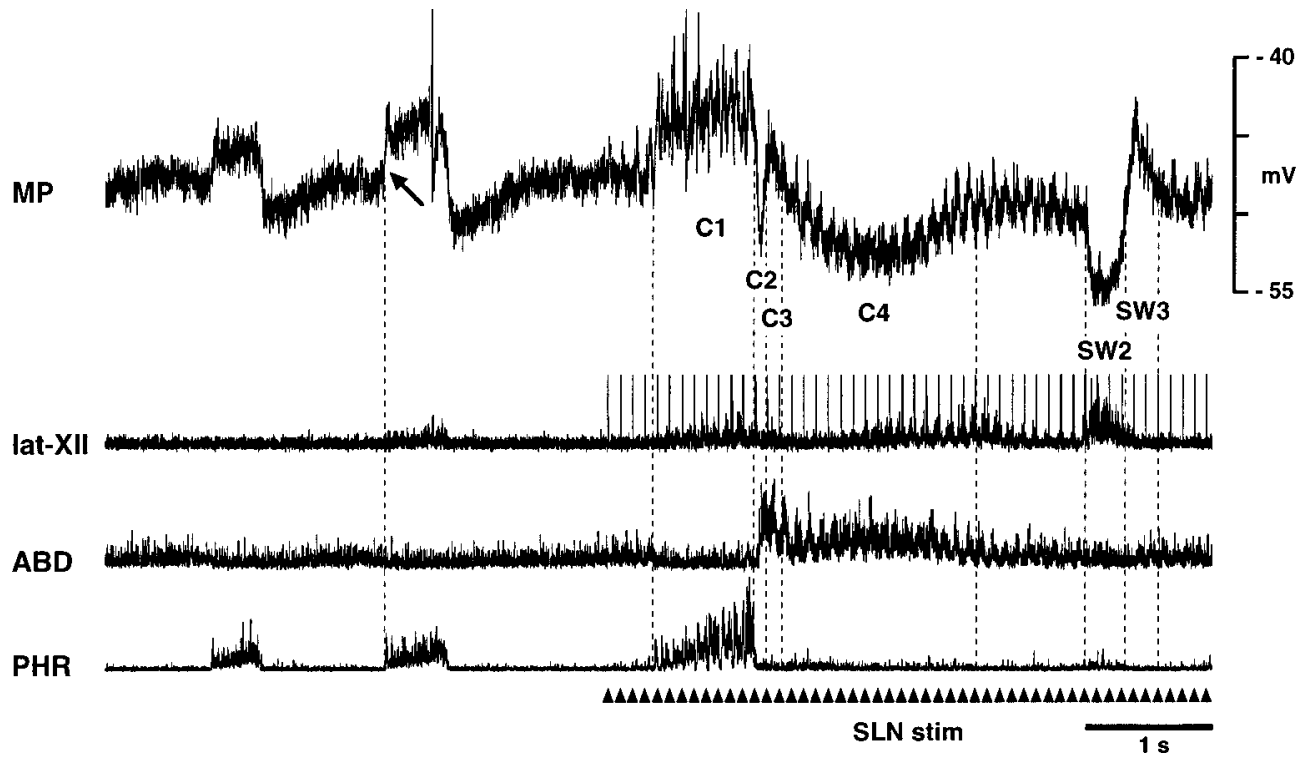

0.01). The duration of SW2 averaged $0.29 \pm 0.05 \mathrm{sec}$. The amplitude of SW2 did not differ from that of the depolarization at the I-E transition of coughing.

There was marked hyperpolarization of ILMs during the hypoglossal burst (stage SW2), followed by depolarization at the offset of the burst (stage SW3) (Fig. 5). The amplitude of SW2 $(-7.7 \pm 5.1 \mathrm{mV}$; range, -2.4 to $-18.5 \mathrm{mV})$ was greater than control expiratory-related hyperpolarization $(-3.5 \pm 1.7 \mathrm{mV}$; range, -1.2 to $-5.3 \mathrm{mV})(p<0.05)$, but the subsequent depolarization (SW3) $(2.4 \pm 1.6 \mathrm{mV}$; range, $0.0-4.1 \mathrm{mV})$ did not differ from control inspiratory-related depolarization $(3.1 \pm 1.8 \mathrm{mV}$; range, $1.0-5.2 \mathrm{mV}$ ). The respective duration of SW2 and SW3 was $0.35 \pm 0.27$ and $0.27 \pm 0.08$ sec.

\section{Fictive sneezing}

The motor pattern of the phrenic and abdominal nerves during sneezing, which consists of burst activity of the abdominal nerve after phrenic nerve activation, was similar to that during coughing. A difference between the motor patterns of sneezing and coughing was observed in the activity of the lat-XII, which was sharply activated during the latter part of the expiratory phase of sneezing (Figs. 6, 7), but it showed only minor activity during 
A

eupnea

MP

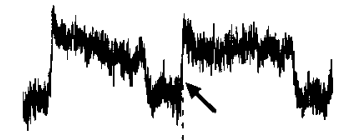

PHR

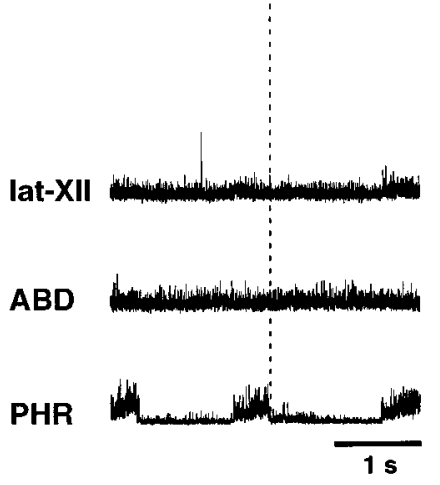

B

sneezing

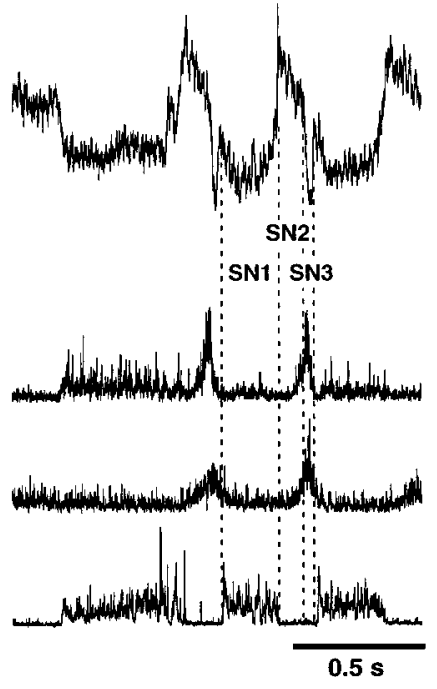
C $\begin{aligned} & \text { aspiration } \\ & \text { reflex }\end{aligned}$
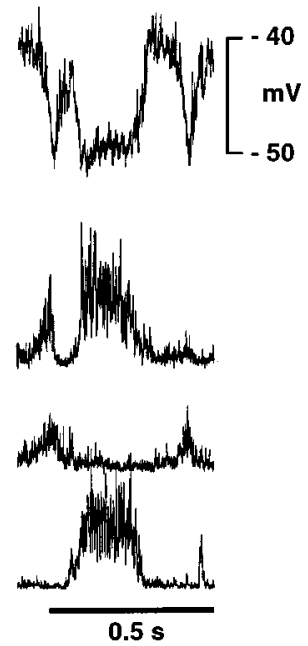

Figure 6. Intracellular recordings from an ELM during sneezing and the aspiration reflex. $A, B$, and $C$ were recorded during eupnea, stimulation of the nasal mucosa, and stimulation of the nasopharyngeal mucosa, respectively. $B$, Fictive sneezing is identified by simultaneous burst activities of the abdominal and lat-XII nerves after phrenic activation during nasal stimulation. This neuron hyperpolarized during the inspiratory phase of sneezing ( $S N 1)$ and then depolarized abruptly at the I-E transition (SN2). Subsequently, the neuron repolarized sharply during the latter part of the abdominal burst $(S N 3)$. $C$, Fictive aspiration reflex, identified by burst activities of the phrenic and lat-XII nerves (see also Fig. 8). This neuron hyperpolarized abruptly during the phrenic burst. Presumptive resting potentials of this ELM was measured at the arrow.

coughing (Figs. 3-5), as reported by Satoh et al. (1998). Thus, we regarded burst activity of the lat-XII and abdominal nerves together during nasal stimulation as indicating fictive sneezing.

We recorded membrane potential changes in six ELMs and five ILMs during fictive sneezing. The respective patterns of membrane potential changes in ELMs and ILMs during sneezing were similar to that of type A ELMs and ILMs during coughing, with the exception of the stage C4. ELMs hyperpolarized during the inspiratory phase of sneezing (stage SN1) and then depolarized at the I-E transition (stage SN2) (Fig. 6B). The onset of this depolarization was before the abdominal burst. Subsequently, there was a brisk repolarization of ELMs during the latter part of the lat-XII and abdominal nerve burst (stage SN3) (Fig. 6B). The amplitude of the depolarization during SN2 $(8.1 \pm 1.85 \mathrm{mV}$; range, $6.0-10.0 \mathrm{mV}$ ) was greater than that of expiratory-related depolarization $(6.3 \pm 2.0 \mathrm{mV}$; range, $3.6-8.0 \mathrm{mV})(p<0.01)$, but the amplitude of the subsequent hyperpolarization (SN3) $(-1.51 \pm 2.43 \mathrm{mV}$; range, 2.4 to $-4.24 \mathrm{mV})$ did not differ from control inspiratory-related hyperpolarization $(-0.9 \pm 0.9 \mathrm{mV}$; range, 0.0 to $-2.0 \mathrm{mV}$ ). The duration of stages SN2 and SN3 was $0.12 \pm 0.04$ and $0.05 \pm 0.01 \mathrm{sec}$, respectively.

The membrane potential trajectories of ILMs during fictive sneezing were opposite to those of ELMs. ILMs depolarized during the inspiratory phase of sneezing (stage SN1) and then hyperpolarized at the I-E transition (stage SN2) (Fig. 7 $A, B$ ). The trajectory of this hyperpolarization was decrementing in pattern. ILMs depolarized briskly during the latter part of the expiratory burst (stage SN3) (Fig. 7B). The amplitude of hyperpolarization during SN2 $(-5.8 \pm 3.6 \mathrm{mV}$; range, -3.0 to $-10.8 \mathrm{mV})$ did not differ from expiratory-related hyperpolarization $(-2.2 \pm 2.0 \mathrm{mV}$; range, -0.9 to $-4.8 \mathrm{mV}$ ), nor did the depolarization during SN3 (7.4 $\pm 6.5 \mathrm{mV}$; range, $3.2-17.0 \mathrm{mV}$ ) differ from inspiratoryrelated depolarization $(4.19 \pm 0.92 \mathrm{mV}$; range, $3.0-5.2 \mathrm{mV})$. The duration of stages SN2 and SN3 averaged $0.12 \pm 0.05$ and $0.04 \pm$ $0.01 \mathrm{sec}$, respectively.

There were differences between the patterns of membrane potential changes in coughing and sneezing. First, the repolarization of ELMs at the I-E transition during sneezing was larger than that during coughing because the difference in membrane potential of ELMs between stages SN2 and SN3 of sneezing $(9.6 \pm 3.8 \mathrm{mV}$; range, $4.0-12.0 \mathrm{mV})$ was greater than that between stages $\mathrm{C} 2$ and C3 of coughing $(p<0.05)$. Second, the amplitude of ILM depolarization during SN3 of sneezing was greater than during C3 of coughing $(p<0.05)$. Third, persistent depolarization of ELMs and hyperpolarization of ILMs with continuation of the abdominal burst (stage C4 of coughing) was not observed during sneezing. Finally, during sneezing, no ELM exhibited continuous depolarization throughout the abdominal burst, like type B ELMs during coughing; all showed transient repolarization, like type A ELMs.

\section{The fictive aspiration reflex}

In four cats, we compared the activities of the phrenic, abdominal, and lat-XII nerves during nasopharyngeal stimulation after paralysis with the electromyographic activities of the diaphragm, external oblique, and styloglossus muscles during the real aspiration reflex induced by nasopharyngeal stimulation before paralysis. Nasopharyngeal stimulation in nonparalyzed cats (Fig. 8A) caused repeated highly recruited activities of the diaphragm, i.e., the aspiration reflex (Korpas and Tomori, 1979). This powerful inspiratory activity caused a negative tracheal pressure of $\sim 40 \mathrm{~cm}$ of $\mathrm{H}_{2} \mathrm{O}$ and was associated with strong activation of the styloglossus muscle. In contrast to coughing and sneezing, diaphragmatic activity was not followed by an abdominal muscle burst. Figure $8 B$ shows respiratory and tongue nerve activities during nasopharyngeal stimulation in paralyzed cats. The phrenic and lat-XII nerves were strongly and simultaneously activated without abdominal nerve activation. The pattern of nerve activities was similar to that of the muscle activities observed before paralysis. Using this "fictive aspiration reflex," we conducted intracellular recordings from five ELMs and five ILMs in paralyzed cats.

Because a polyethylene tube inserted through the nasal cavity could stimulate both the nasal and nasopharyngeal mucosae simultaneously, the aspiration reflex was sometimes evoked in conjunction with sneezing (Fig. 7A). ELMs hyperpolarized abruptly during the strong phrenic activation (Fig. 6C) and showed bell-shaped or plateau-like patterns of inhibitory inputs. The amplitude of this hyperpolarization $(-3.7 \pm 1.4 \mathrm{mV}$; range, 


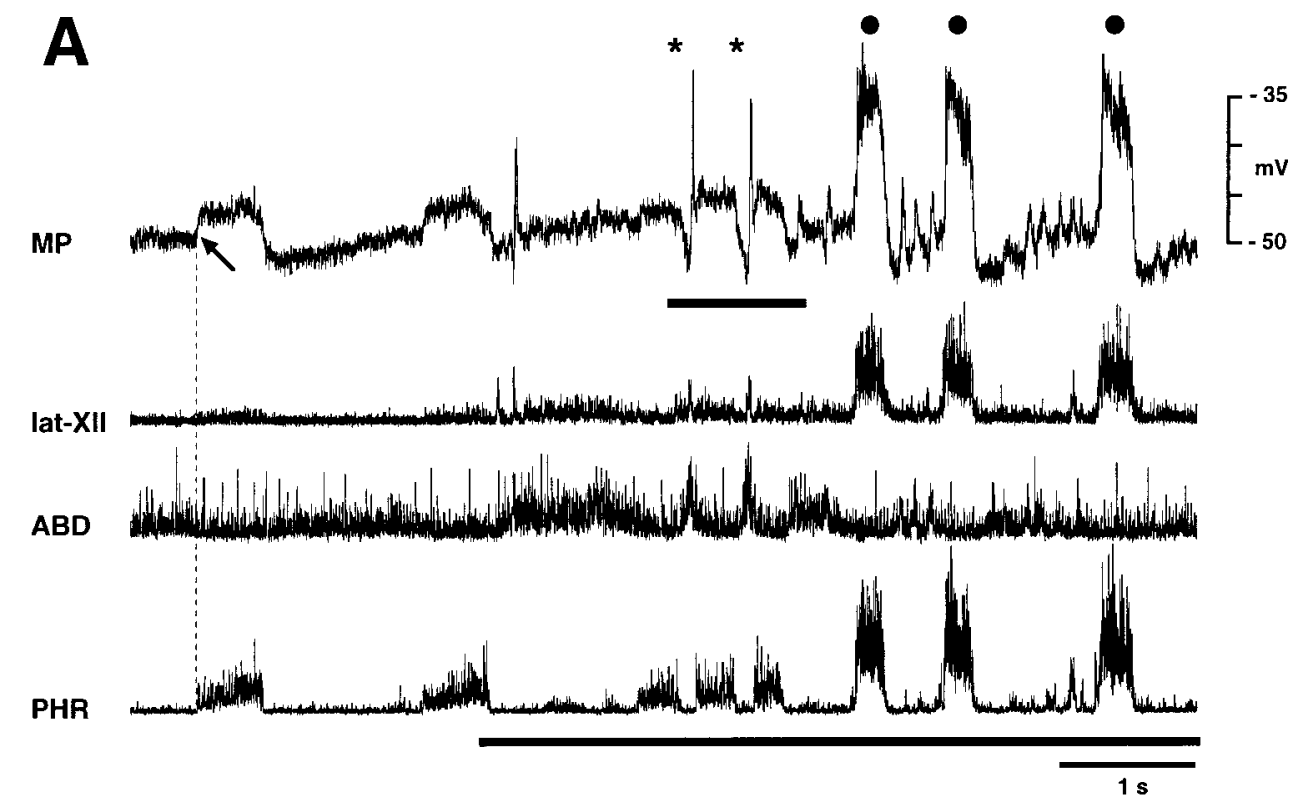

Figure 7. Recording from an ILM during sneezing (asterisks) and aspiration reflexes ( filled circles). A, This neuron depolarized powerfully during the aspiration reflex. Thick horizontal line at the bottom indicates stimulation of the nasopharyngeal mucosa. $B$, High-speed recording of the period indicated by a horizontal line below $M P$ in $A$ showing sneezing episodes. This ILM depolarized during the inspiratory phase of sneezing (SN1), hyperpolarized after the I-E transition (SN2), and then depolarized again abruptly during the latter part of the abdominal burst (SN3). Presumptive resting potential of this ILM was measured at the arrow.

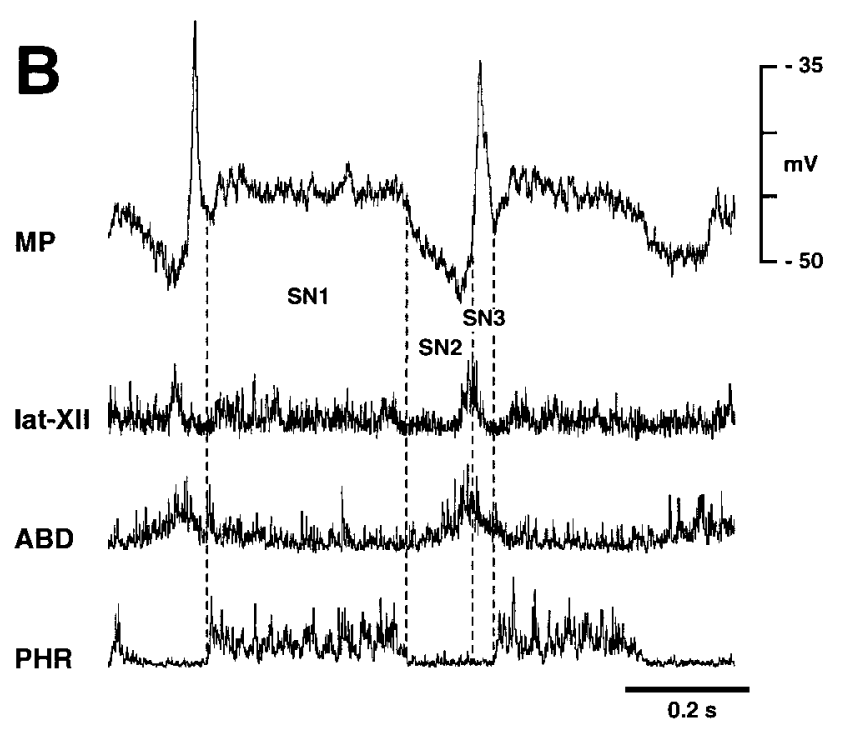

-1.6 to $-5.0 \mathrm{mV}$ ) was greater than control inspiratory-related hyperpolarization $(-0.86 \pm 0.88 \mathrm{mV}$; range, -0.1 to $-2.0 \mathrm{mV})$ $(p<0.05)$. Its duration averaged $0.23 \pm 0.03 \mathrm{sec}$. ILMs depolarized very strongly during the inspiratory reflex (Fig. 7A) and demonstrated bell-shaped patterns of membrane potential trajectories. The amplitude of this depolarization $(13.8 \pm 4.0 \mathrm{mV}$; range, 9.2-18.0 $\mathrm{mV}$ ) was greater than control inspiratory-related depolarization $(4.2 \pm 0.92 \mathrm{mV})(p<0.05)$, and its duration was $0.26 \pm 0.02 \mathrm{sec}$.

\section{DISCUSSION}

This report is the first to describe the membrane potential changes in laryngeal motoneurons during vocalization, coughing, sneezing, swallowing, and the aspiration reflex. The respiratoryrelated pattern of membrane potential changes in laryngeal motoneurons was altered during these behaviors. This work forms the foundation for further investigation into the neuronal networks that generate these different behaviors and will help address the question of whether these behaviors result from reor- ganization of a single rhythm generating system or a number of coordinated systems.

\section{Vocalization}

The vocal fold adductor is strongly activated during PCS-induced vocalization (Yamanaka et al., 1993). Indeed, many laryngeal motoneurons become active synchronously with vocalization (Yajima and Larson, 1993). Consistent with this, ELMs depolarized strongly during vocalization. The question arises whether vocalization-related adductor activation is caused by synaptic inputs from the same region that produces respiratory-related laryngeal activity or from outside the respiratory network. Hostege (1989) proposed the final common pathway for vocalization: the projection from the PAG via the nucleus retroambigualis (NRA) to laryngeal motoneurons. Our previous study showed that neurons in the vicinity of the NRA are part of the neuronal network providing vocal-related drives to ELMs but do not participate in producing respiratory-related ELM activity (Shiba et al., 1997). Furthermore, decrementing patterns of membrane 
A before paralysis

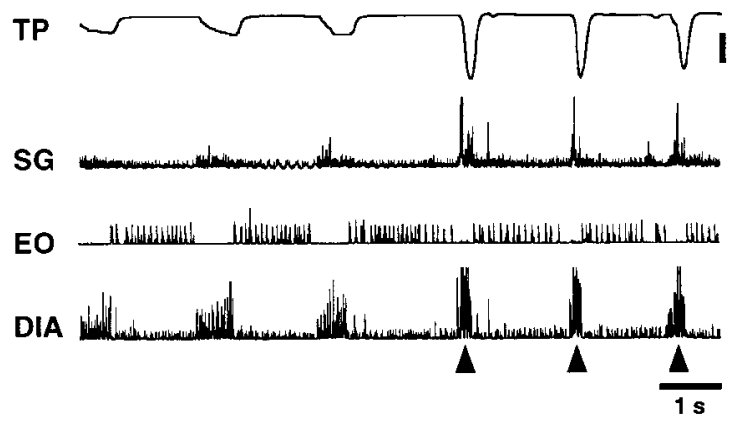

B

after paralysis

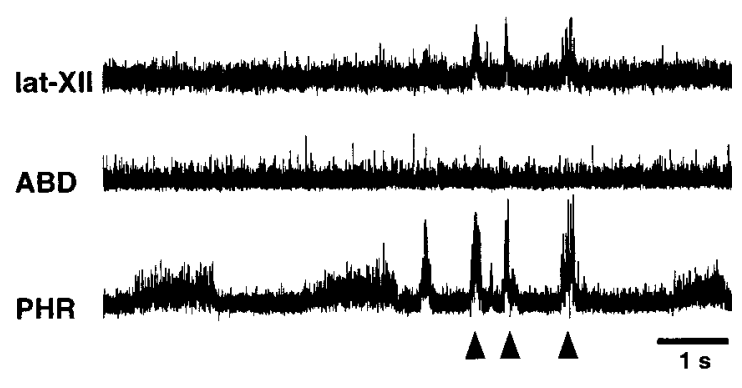

Figure 8. Patterns of correlated muscle and nerve activity during the fictive aspiration reflex. $A$, Motor pattern of the diaphragm $(D I A)$, external oblique $(E O)$, and styloglossus $(S G)$ muscles during the aspiration reflex evoked by mechanical stimulation of the nasopharyngeal mucosa before induction of paralysis. Aspiration reflex episodes (arrowheads) caused strong negative tracheal pressure $(T P)$. $B$, Neurograms of the phrenic, abdominal, and lat-XII nerves during stimulation of the nasopharyngeal mucosa after induction of paralysis. The lat-XII innervates the styloglossus muscle. The motor pattern of activities of these nerves after paralysis was consistent with that of respiratory and tongue muscles before paralysis. Data in $A$ and $B$ were obtained in the same cat. Tracheal pressure calibration: $20 \mathrm{~cm}$ of $\mathrm{H}_{2} \mathrm{O}$.

potential trajectories of ELMs during the expiratory phase in eupnea changed to bell-shaped patterns during vocalization. Based on these findings, we suggest that vocalization is caused by altering the neuronal network, which drives ELMs by the addition of NRA neurons and by changes in the effective synaptic connections; PAG stimulation reorganizes the laryngeal neuronal network to induce vocalization.

The present study shows that recruitment during vocalization varies among ELMs. The intralaryngeal muscles innervated by the RLN, except for the vocal fold abductor, consist of the thyroarytenoid, lateral cricoarytenoid, interarytenoid, thyroepiglottic, and aryepiglottic muscles. The main functional role of the thyroarytenoid, lateral cricoarytenoid, and interarytenoid muscles is vocal fold adduction. The thyroepiglottic and aryepiglottic muscles close the glottis at the level of the ventricular fold. We speculate that this variation in ELM activity may be attributable to differences in the muscles innervated.

Our findings that some ILMs remained depolarized during the vocal phase is consistent with a report that the vocal fold abductor is sometimes activated slightly during PCS-induced vocalization (Yamanaka et al., 1993). We suggest that vocalization-related abductor activity balances vocal fold adduction during vocalization and prevents excessive narrowing of the glottis. The PAG-
NRA projection is not important for PAG-induced abductor activation (Shiba et al., 1997). However, PAG neurons also project, through the PCS, to the region between the Bötzinger complex and rostral ventral respiratory group (BÖT/rVRG) (Sakamoto et al., 1996b), which is a key area for respiratory rhythmogenesis (Smith et al., 1991; Bianchi et al., 1995; Ezure, 1996). Evidence that BÖT augmenting expiratory neurons (EAUG neurons), which inhibit VRG inspiratory neurons (Ezure, 1996), can be silenced by PAG stimulation (Sakamoto et al., 1996a) suggests that these E-AUG neurons may be the synaptic source of ILM depolarization during the vocal phase, as well as the inspiratory phase, during call site stimulation. Furthermore, Larson (1991) raised the possibility that PAG cells send excitatory outputs to ILMs. Thus, we propose that the PAG-BÖT/rVRG projection contributes to stimulus-induced abductor activity.

\section{Coughing}

Coughing events can be divided into four phases related to changes in glottal caliber: the inspiratory, compressive, expulsive, and narrowing phases (Korpas and Tomori, 1979). After the inspiratory phase, the glottis is closed in the compressive phase with powerful expiratory muscle activity, which causes an abrupt rise in tracheal pressure. The glottis then dilates transiently at the peak of tracheal pressure to release an explosive expiratory airflow during the expulsive phase. The glottis then constricts again, i.e., the narrowing phase. We propose that stages $\mathrm{C} 2, \mathrm{C} 3$, and $\mathrm{C} 4$ correspond to the compressive, expulsive, and narrowing phases, respectively.

The phrenic and abdominal nerves did not change in activity during $\mathrm{C} 3$. The majority of BÖT/rVRG respiratory neurons with monosynaptic connections to laryngeal motoneurons (Ezure and Manabe, 1988; Ezure et al., 1989; Jiang and Lipski, 1990) do not exhibit firing patterns synchronized with stage C3 (Oku et al., 1994; Shannon et al., 1996). These respiratory neurons are the origin of respiratory-related laryngeal activity. Therefore, we suggest that, although the respiratory network plays an important role in generating cough-related respiratory activity, laryngeal movement at least during the expulsive phase is caused by drives originating outside the respiratory network. There were two types of ELMs, designated type A and type B. Their difference may be attributable to muscle differences as discussed in the section on vocalization. Our finding that only type A neurons participate in the expulsive phase suggests that the glottis does not completely dilate during the expulsive phase and that there may be the anatomical variation in synaptic sources of expulsive phase control of laryngeal motoneurons.

\section{Swallowing}

Swallowing, which consists of oral, pharyngeal, and esophageal stages, requires highly coordinated upper airway movements (Miller, 1982). During the pharyngeal stage, a bolus is conveyed into the pharyngeal cavity and then passed through the pharyngoesophageal sphincter by involuntary peristaltic activity. Our findings that ELMs depolarized during SW2 and ILMs during SW3 are consistent with the results of previous electromyographic studies (Doty and Bosma, 1956; Umezaki et al., 1998). Our results show that ELMs and ILMs hyperpolarized during SW1 and SW2, respectively. This adductor excitation (ELMs) with abductor inhibition (ILMs) during the pharyngeal stage (SW2) causes strong glottal closure, which protects the lower airway from aspiration. However, the functional significance of the adductor inhibition at the onset of the pharyngeal stage and 
the abductor excitation after the pharyngeal stage are unclear. We speculate that this adductor inhibition causes the intrathoracic pressure to reach an optimal level for deglutition. We suggest that negative intrathoracic pressure produced by low level inspiratory muscle activity against a closed glottis in stage SW2 assists the passage of the bolus from the pharynx to the esophagus. Our previous finding that abductor activation coincides with that of the inferior pharyngeal constrictor (Umezaki et al., 1998) indicates that the glottis is open while the upper esophageal sphincter prevents back-flow of the bolus. We speculate that this glottal opening allows equilibration of intrathoracic with atmospheric pressure during the esophageal stage of swallowing. In contrast to our findings, Zoungrana et al. (1997) reported that presumptive ILMs activated antidromically from the cervical vagus nerve exhibit a simple hyperpolarization without subsequent depolarization during the pharyngeal stage in sheep.

Complex depolarizing-hyperpolarizing waves of membrane potential occur in some pharyngeal and hypoglossal motoneurons during swallowing (Tomomune and Takata, 1988; Zoungrana et al., 1997). Swallowing motoneurons may possess complex intrinsic properties activated by the swallowing drive. Jean et al. (1996) proposed that swallowing neurons in the ventrolateral medulla coordinate the swallowing reflex by outputs to swallowing motoneurons. This is supported by recent studies demonstrating interneurons located dorsomedial to the BÖT/rVRG that project to hypoglossal and/or laryngeal motoneurons and show brief burst firing during swallowing (Ezure et al., 1993; Ono et al., 1998). It seems likely that these neurons are responsible for swallow-related laryngeal activities.

\section{Sneezing}

Laryngeal movements during sneezing are similar to those during coughing; sneezing events also consist of inspiratory, compressive, and expulsive phases. Consistent with this, the membrane potential changes in laryngeal motoneurons during sneezing were similar to those during coughing. The glottis, after inspiratory dilatation, closes completely at the onset of the expiratory phase of sneezing and then dilates abruptly (Korpas and Tomori, 1979). As discussed in the section on coughing, we think that stages SN2 and SN3 correspond to the compressive and expulsive phases, respectively. The main differences we found in the activity of laryngeal motoneurons during coughing and sneezing (see Results) were in the expulsive phase. The greater expiratory airflow rate observed in sneezing (Unno, 1975) may be attributable to these differences in laryngeal motoneuron activities during the expulsive phase.

Based on findings in the present study and other reports showing that most medullary respiratory neurons exhibit discharge patterns consistent with involvement in sneezing but do not change in activity in synchrony with SN3 (Batsel and Lines, 1975, 1978; Jakus et al., 1985; Orem and Brooks, 1986; Wallois et al., 1992, 1997), we conclude that, as for coughing, the central mechanism generating sneezing is intimately connected with the respiratory network but that the respiratory network does not control glottal movement during the expulsive phase of sneezing. Wallois et al. (1997) reported nonrespiratory neurons located near the nucleus of the solitary tract that fired only during the compressive phase of sneezing; it seems likely that these neurons are responsible for sneeze-related laryngeal activity.

\section{The aspiration reflex}

Mechanical stimulation of the nasopharyngeal mucosa caused an aspiration reflex consisting of strong inspiratory effort without subsequent expiration (Korpas and Tomori, 1979). We designated phrenic burst activity without a subsequent abdominal nerve burst during nasopharyngeal stimulation in paralyzed cats a fictive aspiration reflex, because patterns of nerve activity after induction of paralysis were similar to patterns of respiratory motor activity induced by the stimulation during real aspiration episodes. Our results revealed that, in contrast to other upper airway defensive reflexes, simple bell-shaped changes in membrane potential were evoked in laryngeal motoneurons during the aspiration reflex. We think that the large ILM depolarization and ELM hyperpolarization during powerful inspiration facilitates an explosive inspiratory airflow. Our study also revealed that the tongue-back elevator was strongly activated during the aspiration reflex. We think that narrowing of the oral airway caused by this tongue movement enhances nasal airflow during the aspiration reflex, allowing removal of foreign material from the nasopharynx.

\section{REFERENCES}

Amri M, Lamkadem M, Car A (1989) Activity of extrinsic tongue muscles during swallowing in sheep. Brain Res 503:141-143.

Barillot JC, Grélot L, Reddad S, Bianchi AL (1990) Discharge patterns of laryngeal motoneurones in the cat: an intracellular study. Brain Res 509:99-106.

Bartlett DJ (1986) Upper airway motor systems. In: Handbook of physiology, Sec 3, The respiratory system, Vol II (Cherniack NS, Widdicombe JG, eds), pp 223-245. Bethesda, MD: The American Physiological Society.

Batsel HL, Lines AJ (1975) Neural mechanisms of sneeze. Am J Physiol 229:770-776.

Batsel HL, Lines AJ (1978) Discharge of respiratory neurons in sneezes resulting from ethmoidal nerve stimulation. Exp Neurol 58:410-424.

Bianchi AL, Denavit-Saubié M, Champagnat J (1995) Central control of breathing in mammals: neuronal circuitry, membrane properties, and neurotransmitters. Physiol Rev 75:1-45.

Bolser D (1991) Fictive cough in the cat. J Appl Physiol 71:2325-2331.

de Lanerolle NC (1990) A pontine call site in the domestic cat: behavior and neural pathways. Neuroscience 37:201-214.

Doty BW, Bosma JF (1956) An electromyographic analysis of reflex deglutition. J Neurophysiol 19:44-60.

Ezure K (1996) Respiratory control. In: Vestibular autonomic regulation (Miller AD, Yates BJ, eds), pp 53-84. Boca Raton, FL: CRC.

Ezure K, Manabe M (1988) Decrementing expiratory neurons of the Bötzinger complex. II. Direct inhibitory synaptic linkage with ventral respiratory group neurons. Exp Brain Res 72:159-166.

Ezure K, Manabe M, Otake K (1989) Excitation and inhibition of medullary inspiratory neurons by two types of burst inspiratory neurons in the cat. Neurosci Lett 104:303-308.

Ezure K, Oku Y, Tanaka I (1993) Location and axonal projection of one type of swallowing interneurons in cat medulla. Brain Res 632:216-224.

Fung ML, Tomori Z, St. John WM (1995) Medullary neuronal activities in gasping induced by pharyngeal stimulation and hypoxia. Respir Physiol 100:195-202.

Gilliam EE, Goldberg AS (1995) Contractile properties of the tongue muscles: effects of hypoglossal nerve and extracellular motoneuron stimulation in rat. J Neurophysiol 74:547-555.

Grélot L, Milano S (1991) Diaphragmatic and abdominal muscle activity during coughing in the decerebrate cat. NeuroReport 2:165-168.

Grélot L, Milano S, Portillo F, Miller AD, Bianchi AL (1992) Membrane potential changes of phrenic motoneurons during fictive vomiting, coughing, and swallowing in the decerebrate cat. J Neurophysiol 68:2110-2119.

Holstege G (1989) Anatomical study of the final common pathway for vocalization in the cat. J Comp Neurol 284:242-252.

Jakus J, Tomori Z, Stransky A (1985) Activity of bulbar respiratory neurones during cough and other respiratory tract reflexes in cats. Physiol Bohemoslov 34:127-136.

Jean A, Car A, Kessler JP (1996) Brainstem organization of swallowing and its interaction with respiration. In: Neural control of the respiratory muscles (Miller AD, Bianchi AL, Bishop BP, eds), pp 223-237. Boca Raton, FL: CRC. 
Jiang C, Lipski J (1990) Extensive monosynaptic inhibition of ventral respiratory group neurons by augmenting neurons in the Bötzinger complex in the cat. Exp Brain Res 81:639-648.

Jodkowski JS, Guthrie RD, Cameron WE (1989) The activity pattern of phrenic motoneurons during the aspiration reflex: an intracellular study. Brain Res 505:187-194.

Jürgens U (1994) The role of the periaqueductal grey in vocal behaviour. Behav Brain Res 62:107-117.

Kanai T, Wang SC (1962) Localization of the central vocalization mechanism in the brain stem of the cat. Exp Neurol 6:426-434.

Korpas J, Tomori Z (1979) Cough and other respiratory reflexes. Basel: Karger.

Larson CR (1991) On the relation of PAG neurons to laryngeal and respiratory muscles during vocalization in the monkey. Brain Res 552:77-86.

Miller AJ (1982) Deglutition. Physiol Rev 62:129-184.

Nishino T, Honda Y, Kohchi T, Shirahata M, Yonezawa T (1985) Effects of increasing depth of anaesthesia on phrenic nerve and hypoglossal nerve activity during the swallowing reflex in cats. $\mathrm{Br} \mathrm{J}$ Anaesth 57:208-213.

Oku Y, Tanaka I, Ezure K (1994) Activity of bulbar respiratory neurons during fictive coughing and swallowing in the decerebrate cat. J Physiol (Lond) 480:309-324.

Ono T, Ishiwata Y, Inaba N, Kuroda T, Nakamura Y (1998) Modulation of the inspiratory-related activity of hypoglossal premotor neurons during ingestion and rejection in the decerebrate cat. J Neurophysiol $80: 48-58$.

Orem J, Brooks EG (1986) The activity of retrofacial expiratory cells during behavioral respiratory responses and active expiration. Brain Res 374:409-412.

Sakamoto T, Katada A, Nonaka S, Takakusaki K (1996a) Activities of expiratory neurones of the Bötzinger complex during vocalization in decerebrate cats. NeuroReport 7:2353-2356.

Sakamoto T, Nonaka S, Katada A (1996b) Control of respiratory muscles during speech and vocalization. In: Neural control of the respiratory muscles (Miller AD, Bianchi AL, Bishop BP, eds), pp 249-258. Boca Raton, FL: CRC.

Satoh I, Shiba K, Kobayashi N, Nakajima Y, Konno A (1998) Upper airway motor outputs during sneezing and coughing in decerebrate cats. Neurosci Res 32:131-135.

Shannon R, Bolser DC, Lindsey BG (1996) Neural control of coughing and sneezing. In: Neural control of the respiratory muscles (Miller AD, Bianchi AL, Bishop BP, eds), pp 213-222. Boca Raton, FL: CRC.
Shiba K, Umezaki T, Zheng Y, Miller AD (1996) Fictive vocalization in the cat. NeuroReport 7:2139-2142.

Shiba K, Umezaki T, Zheng Y, Miller AD (1997) The nucleus retroambigualis controls laryngeal muscle activity during vocalization in the cat. Exp Brain Res 115:513-519.

Smith JC, Ellenberger HH, Ballanyi K, Richter DW, Feldman JL (1991) Pre-Bötzinger complex: a brainstem region that may generate respiratory rhythm in mammals. Science 254:726-729.

Tomomune N, Takata M (1988) Excitatory and inhibitory postsynaptic potentials in hypoglossal motoneurons during swallowing. Exp Brain Res 71:262-272.

Umezaki T, Shiba K, Zheng Y, Miller AD (1998) Upper airway motor outputs during vomiting versus swallowing in the decerebrate cat. Brain Res 781:25-36.

Unno T (1975) Cough and sneeze. J Otolaryngol Jpn 78:1-9.

Wada K (1994) Brainstem mechanisms of vocalization analyzed by electrical stimulation and chemical stimulation of sodium glutamate in cats. J Otolaryngol Jpn 97:1456-1463.

Wallois F, Macron V, Jounieaux V, Duron B (1992) Influence of trigeminal nasal afferents on bulbar respiratory neuronal activity. Brain Res 599:105-116.

Wallois F, Bodineau L, Macron JM, Marlot D, Duron B (1997) Role of respiratory and non-respiratory neurones in the region of the NTS in the elaboration of the sneeze reflex in cat. Brain Res 768:71-85.

Widdicombe JG (1986) Reflexes from the upper respiratory tract. In: Handbook of physiology, Sec 3, The respiratory system, Vol II, Control of breathing (Cherniack NS, Widdicombe JG, eds), pp 363-394. Bethesda, MD: The American Physiological Society.

Wyke BD, Kirchner JA (1976) Neurology of the larynx. In: Scientific foundations of otolaryngology (Hinchcliffe R, Harrison D, eds), pp 546-574. London: Heinemann.

Yajima Y, Larson CR (1993) Multifunctional properties of ambiguous neurons identified electrophysiologically during vocalization in the awake monkey. J Neurophysiol 70:529-540.

Yamanaka Y, Sakamoto T, Wada K, Nakajima Y (1993) Activities of the intralaryngeal muscles during electrically induced vocalization in decerebrate cats. Neurosci Res 17:77-81.

Zhang SP, Davis PJ, Bandler R, Carrive P (1994) Brain stem integration of vocalization: role of the midbrain periaqueductal gray. J Neurophysiol 72:1337-1356.

Zoungrana OR, Amri M, Car A, Roman C (1997) Intracellular activity of motoneurons of the rostral nucleus ambiguus during swallowing in sheep. J Neurophysiol 77:909-922. 